\title{
Las faunas de mamíferos del Mioceno continental de la Península Ibérica
}

Jordi Agustí | ICREA. Institut Català de Paleoecologia Humana i Evolución social (IPHES). Universitat Rovira i Virgili (Tarragona)

URL de la contribución <www.iaph.es/revistaph/index.php/revistaph/article/view/4179>

\section{RESUMEN}

En este trabajo se realiza un resumen de la sucesión de faunas de mamíferos continentales del Mioceno de la Península Ibérica. La Península Ibérica cuenta con el mejor registro continental del Mioceno de Europa, llegando a cubrir todo el rango estratigráfico de este sistema, desde el Mioceno basal hasta el límite con el Plioceno. Ello es debido a la existencia de un notable conjunto de cuencas neógenas endorreicas, como es el caso de las cuencas del Vallès-Penedès, Ebro, Calatayud-Daroca, Teruel, Duero, Tajo, Cabriel, Fortuna, Guadix-Baza y Granada. Este extraordinario registro geológico y paleontológico ha permitido la definición de una serie de pisos mastológicos que permiten seguir sobre una base estratigráfica la evolución de las faunas de mamíferos durante el Mioceno. Estos pisos mastológicos corresponden al Rambliense (Mioceno inferior, definido en la cuenca de Teruel), Aragoniense (Mioceno inferior y medio, definido en la cuenca de Calatayud-Daroca), Vallesiense (base del Mioceno superior, definido en la cuenca del VallèsPenedès), Turoliense (Mioceno superior, definido en la cuenca de Teruel) y Ventiense (Mioceno terminal, definido en la cuenca del Cabriel). Las secuencias contenidas en estos pisos permiten trazar la evolución completa de las faunas de mamíferos continentales en la Península Ibérica.

\section{Palabras clave}

Fauna | Mamíferos | Mioceno | Península Ibérica | 


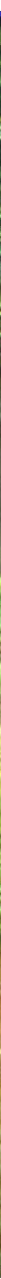

Reconstrucción de la fauna del yacimiento de Sant Quirze | dibujo Mauricio Antón, autor de todas las reconstrucciones de la fauna que ilustran este trabajo 


\section{INTRODUCCIÓN}

La Península Ibérica cuenta con el mejor registro continental del Mioceno de Europa y uno de los más completos a nivel global. Este registro cubre todo el rango estratigráfico de este sistema, desde el Mioceno basal hasta el límite con el Plioceno. La calidad y continuidad de este registro se fundamenta en la existencia de numerosas cuencas endorreicas como es el caso del Vallès-Penedès, Ebro, Calatayud-Daroca, Teruel, Duero, Tajo (también conocida como Depresión Intermedia) y otras cuencas de menores dimensiones. No en vano la primera referencia a un yacimiento miocénico de vertebrados se remonta a la primera mitad del siglo XVIII, cuando Fray B. Jerónimo Feijoo reseña en su Teatro crítico Universal la existencia de un osario en la localidad turolense de Concud. A partir del siglo XX, el extraordinario registro del Mioceno ibérico dio lugar a la definición de una serie de pisos mastológicos, a la manera de los pisos mastológicos definidos en América del Norte, los cuales llegan a cubrir todo el rango del Mioceno. Los primeros de estos pisos fueron definidos en los años 50 del siglo pasado por el impulsor de la paleontología de vertebrados en España, Miquel Crusafont. Crusafont se dio cuenta de que los pisos al uso para referirse a las faunas de mamíferos del Mioceno ibérico, y que correspondían a pisos procedentes de las cuencas del este de Europa (Meótico, Pontiense), no podían aplicarse a las secuen-

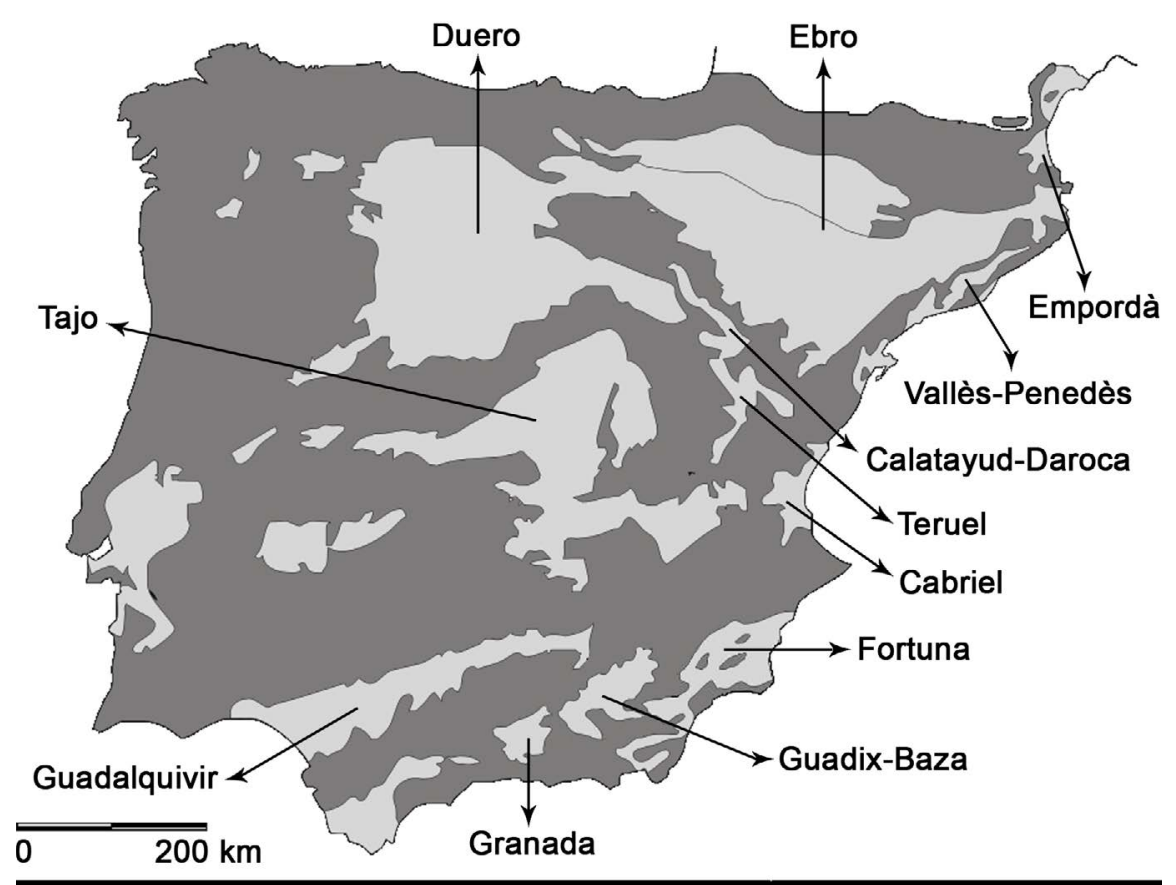


cias del Mioceno superior español. Es así como para las primeras faunas con el équido Hipparion propuso el piso Vallesiense (en referencia a la cuenca del Vallès-Penedès) para sustituir al término Meótico aplicado hasta entonces. Para las faunas del Mioceno más superior (Pontiense en la estratigrafía de Europa oriental) propuso el piso Turoliense (en referencia a la cuenca de Teruel). Con posterioridad, los asistentes al Simposio Internacional sobre Bioestratigrafía de Mamíferos celebrado en Munich en 1975 decidieron proponer nuevos pisos mastológicos que cubriesen todo el Néogeno. Es así como en 1977 Daams, Freudenthal y van der Weerd definieron el piso Aragoniense, con estratotipo en la cuenca de Calatayud-Daroca, para cubrir el rango estratigráfico de Mioceno medio. Este mismo equipo propuso en 1987 el piso Rambliense, para cubrir el tramo inferior del Mioceno. Finalmente, en 1984, Jorge Morales, del Museo Nacional de Ciencias Naturales de Madrid (CSIC) propuso el piso Ventiense para referirse a la parte terminal del Mioceno (anteriormente englobada dentro del Turoliense).

\section{EL RAMBLIENSE (ENTRE 24 Y 17 MILLONES DE AÑOS)}

El Rambliense fue definido por Daams, Freudenthal y Álvarez-Sierra (1981) en la cuenca de Teruel. El nombre hace referencia al Arroyo del Ramblar, cerca de la localidad de Navarrete del Río, donde se estableció el estratotipo del piso. Dentro del Rambliense sus autores pudieron distinguir dos estadios faunísticos diferentes; uno inferior (zona Z) y otro superior (zona A). Entre los micromamíferos, las faunas incluidas en la zona $Z$ están caracterizadas por la presencia de cricétidos (hámsteres) arcaicos de los géneros Eucricetodon y Melissiodon y un variada fauna de glíridos (lirones) correspondientes a diferentes géneros: Peridyromys, Microdyromys, Simplomys, Pseudodryomys y otros. También están bien representados los eómidos del género Ligerimys, pertenecientes a una familia extinta de roedores arborícolas, algunos de los cuales sabemos que poseían un patagio que les permitía planear de árbol en árbol. Las faunas de grandes mamíferos de inicios del Rambliense están sobre todo representadas en las localidades de Cetina de Aragón (cuenca del Duero) (GINSBURG; MORALES; SORIA, 1994; VAN DER Made, 1994), Valquemado, Loranca (cuenca del Tajo) (ALCALÁ; MORALES; SORIA, 1990; VAN DER MADE, 1990) y Navarrete del Río (cuenca de Teruel) (MOYA-SOLA, 1987).

Estas faunas están básicamente compuestas por una variada gama de artiodáctilos, que incluye suidos relacionados con los actuales pécaris (Paleochoerus, Lorancahyus) pero también verdaderos cerdos salvajes como Hyotherium meissneri e Hyotherium major, ambos presentes en Cetina de Aragón. También está presente en Loranca Brachyodus, un miembro de la familia de los antracotéridos, que algunos autores relacionan con los hipopótamos. Entre los no suiformes encontramos a Cainotherium, un 


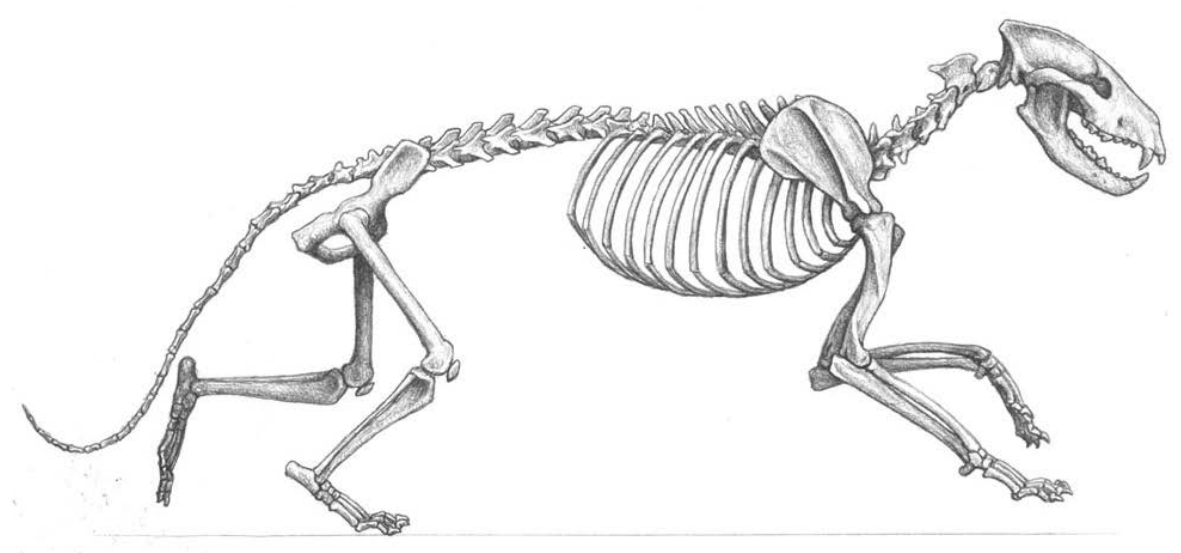

Esqueleto del anficiónido Amphicyon

género de pequeños artiodáctilos del tamaño de una liebre cuyas características craneales (grandes bulas timpánicas) indican una posible adaptación a espacios abiertos. Por lo que respecta a los rumiantes, en Cetina de Aragón se encuentra una amplia representación de ciervos relacionados con los actuales ciervos almizcleros del lejano oriente, como Andegameryx, Bedenomeryx, Oriomeryx o Dremotherium (MORALES; GINSBURG; SORIA, 1986). Como los actuales ciervos almizcleros, estos rumiantes carecían de las características astas que hoy exhiben los actuales cérvidos. Un hecho interesante es la presencia en esta época de los primeros representantes de los jiráfidos, representados por los géneros Teruelia (Navarrete del Río) y Lorancameryx (Loranca). Estos primitivos jiráfidos no presentaban los largos cuellos de las jirafas actuales pero sí los característicos apéndices craneales sobre las órbitas. Entre los perisodáctilos hay que destacar la presencia en Cetina de Aragón de un pequeño tapir (Protapirus) y de un rinoceronte de hábitos acuáticos (Protaceratherium). Este último carecía de los característicos apéndices córneos que hoy exhiben los actuales rinocerontes. Los carnívoros dominantes en esta época pertenecen a la familia de los anficiónidos, popularmente conocidos como perros-oso. Su dentición era similar a la de los cánidos, pero su estructura y dimensiones eran más semejantes a las de los actuales osos. Este es el caso de Amphicyon giganteus, presente en Valquemado y Loranca, cuyos machos podían alcanzar más de 300 kilos de peso. Un segundo anficiónido de menor talla y más grácil, Ysengrinia, está también presente en Cetina de Aragón. Junto a estos grandes carnívoros, los félidos están representados por Pseudaelurus (Loranca), un pequeño felino del tamaño de un gato salvaje que probablemente depredaba sobre los pequeños roedores arborícolas que poblaban los bosques ibéricos de principios del Mioceno.

El tránsito del Rambliense inferior al Rambliense superior no provocó apenas cambios entre las asociaciones de micromamíferos. Tan sólo cabe 
reseñar la extinción de los cricétidos de origen oligocénico del género Eucricetodon, de manera que esta familia quedó reducida tan sólo al peculiar género Melissiodon. Es por ello que esta etapa del Mioceno prácticamente sin hámsteres es referida como la del "Cricetid vacuum" (DAAMS; FREUDENTHAL; ÁLVAREZ-SIERRA, 1981). Por el contrario, entre los grandes mamíferos asistimos a una importante revolución. Y es que África, hasta entonces una especie de continente-isla desde su separación de la Antártida que había desarrollado su propia fauna autóctona de mamíferos, colisionó con Eurasia en la zona del Próximo Oriente. En ese momento, elementos de extracción estrictamente africana penetraron en Europa y viceversa (AGUSTí; ANTÓN, 2002). Este momento de intercambio entre las faunas de grandes mamíferos se encuentra representado en diversos yacimientos de las cuencas del Vallès-Penedès (Molí Calopa, Costablanca, Sant Andreu de la Barca) (AGUSTí; CABRERA; MOYÀ-SOLÀ, 1985; CASANOVASVILAR; MADERN; ALBA et ál., 2016) y Calatayud-Daroca (Agreda, Moratilla) (ALCALÁ; MORALES; SORIA, 1990; VAN DER MADE, 1990). Así, entre los elementos de origen africano se encuentran proboscídeos de los géneros Gomphoterium y Prodeinotherium, parientes muy lejanos de los actuales elefantes. Gomphotherium angustidens, el gonfoterio más común en el Mioceno inferior europeo, constituye una especie típica del género. De talla moderada (no más de 3 metros hasta la cruz, como el actual elefante asiático), su cráneo era alargado y presentaba dos cortas defensas divergentes dirigidas hacia abajo. La mandíbula era así mismo muy larga y anteriormente espatulada, culminando en dos incisivos algo menos desarrollados que los superiores. Su dentición típica a base de grandes tubérculos redondeados indica un régimen basado en frutos y vegetales blandos. Pero Gomphotherium no fue el único tipo de proboscídeo que colonizó Eurasia desde Africa durante el Mioceno inferior. Una forma muy particular, Prodeinotherium, acompañará a las sucesivas especies de mastodontes a lo largo de todo el Mioceno. Los dinoterios constituyen un grupo completamente aparte de proboscídeos, que evolucionó independientemente de la línea que dio lugar a gonfoterios y elefantes. Los molares de los dinoterios eran muy diferentes de los de cualquier proboscídeo, constituidos por pares de crestas cortantes y no por tubérculos aislados, como los mastodontes. A diferencia de los gonfoterios, el cráneo de los dinoterios era corto y mostraba dos grandes defensas. Pero a diferencia de los actuales elefantes, estas defensas no se situaban en el maxilar superior (que carecía de incisivos) sino en la mandíbula. Estos dos incisivos, que se hacían cada vez mayores con la edad, se recurvaban hacia abajo y hacia atrás, en una extraña disposición cuya función es aun hoy discutida.

Las faunas del Rambliense superior, sin embargo, no sólo se vieron enriquecidas por la llegada de inmigrantes asiáticos sino también por Anchitherium, un pequeño équido procedente de América del Norte. Aunque perteneciente a la familia que hoy agrupa a los caballos, Anchitherium mostraba unos caracteres muy diferentes de los actuales équidos. Así, presentaba

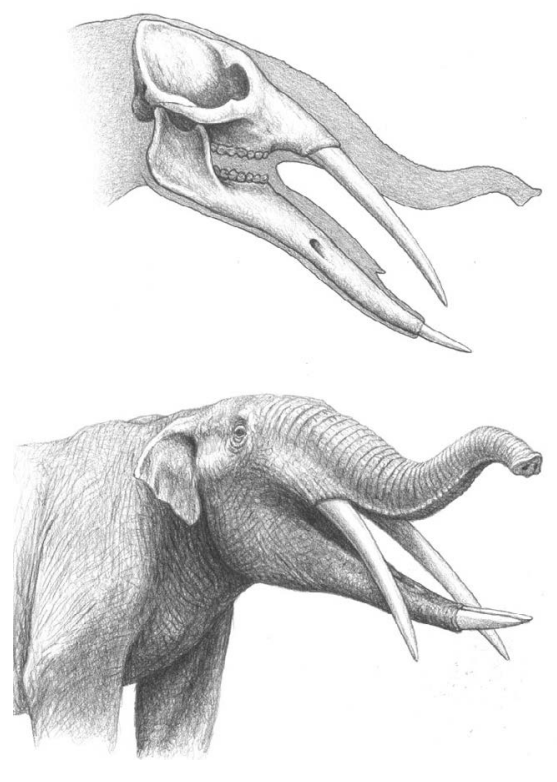

Cráneo de Gomphotherium 


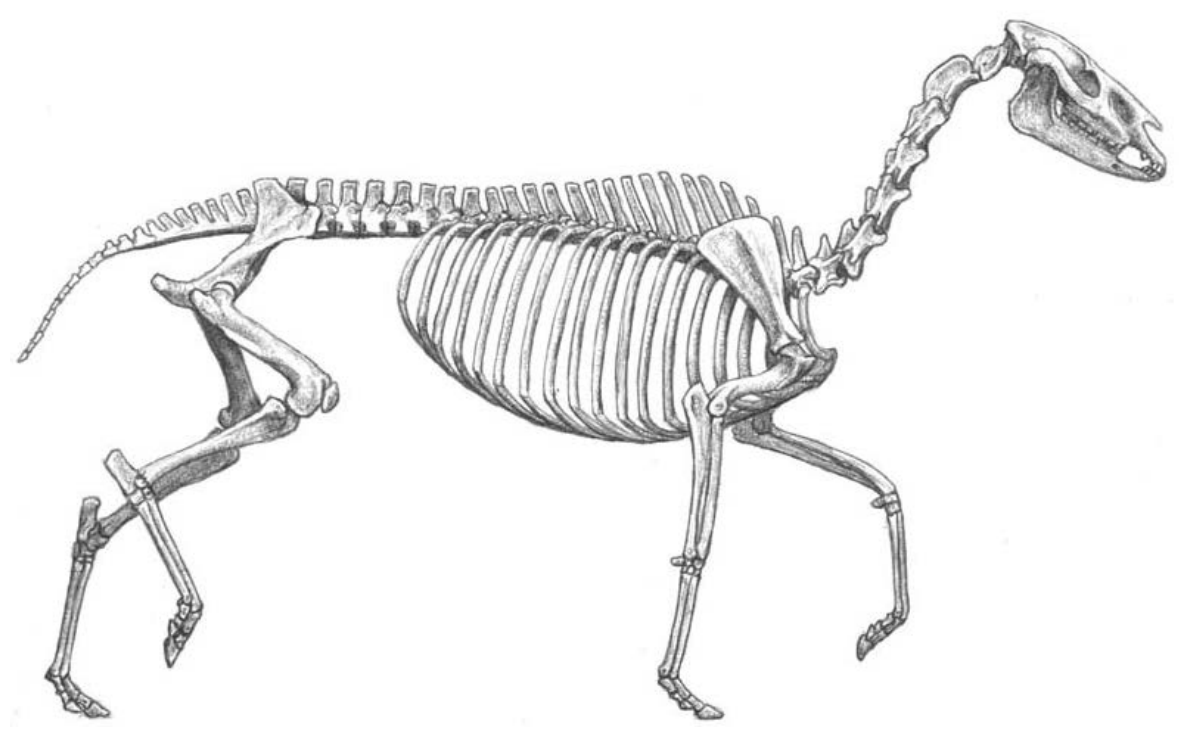

tres dedos funcionales en cada pata y su dentición era de corona baja y no de corona alta, adaptada al consumo de hojas y vegetales blandos. Junto a estos grandes herbívoros se encuentran suidos (Hyotherium, Aureliachoerus, Xenohyus; VAN DER MADE, 1990) y cérvidos de los géneros Procervulus y Acteocemas (AZANZA; MENÉNDEZ, 1990). Estos últimos estaban ya dotados de unas pequeñas astas.

\section{EL ARAGONIENSE INFERIOR (ENTRE 17 Y 16 MILLONES DE AÑOS)}

El piso Aragoniense fue establecido por Daams, Freudenthal y Van Der Weerd (1977) en la cuenca de Calatayud-Daroca, con sección tipo en el área de Daroca-Villafeliche. El Aragoniense cubre el final de Mioceno inferior y todo el Mioceno medio. La base de este piso está definida por el final del "Cricetum vacuum" y la llegada de nuevos géneros de cricétidos que caracterizarán buena parte del Mioceno: Democricetodon, Megacricetodon, Eumyarion y otros. Aparte de la cuenca de Calatayud-Daroca, donde fue definido, el Aragoniense está ampliamente representado en las cuencas del Vallès-Penedès, Tajo $y$, en menor medida, Duero (AGUSTí; CABRERA; MOYÀ-SOLÀ, 1985; CASANOVAS-VILAR; MADERN; ALBA et ál., 2016; ALCALÁ; MORALES; SORIA, 1990; VAN DER MADE, 1990). Dentro del Aragoniense, podemos diferenciar un Aragoniense inferior, correspondiente todavía al Mioceno inferior, un Aragoniense medio y un Aragoniense superior, correspondientes al Mioceno medio. El Aragoniense inferior está sobre todo representado en las cuencas del Vallès-Penedès (yacimientos de El Canyet, Sant Mamet, Can Canals, Els Casots, entre otros), CalatayudDaroca (Artesilla) y Tajo (Córcoles). También cabe reseñar el yacimiento 
de Bunyol en la Comunidad Valenciana. El yacimiento de Els Casots, en el Vallès-Penedès, constituye un perfecto ejemplo de las faunas de la base del Aragoniense (Agustí; Llenas, 1993; CASANOVAS-VILAR; MADERN; ALBA et ál., 2016). La fauna de Els Casots incluye elementos persistentes del Rambliense, como los proboscídeos de los géneros Gomphoterium y Prodeinotherium, los pequeños artiodáctilos del género Cainotherium, los ciervos del género Procervulus, dotados de unas pequeñas astas que tan sólo mostraban un candil, los "perros-osos" del género Amphicyon (Amphicyon giganteus y el más grácil y pequeño Amphicyon olisiponensis) y los pequeños felinos del género Pseudaelurus.

Pero junto a estos elementos persistentes del Rambliense, las faunas de principios del Aragoniense se ven enriquecidas por nuevos elementos. Entre los suidos, un nuevo género de cerdos salvajes, Bunolistridon, se hace dominante. Abundan también los tragúlidos del género Dorcatherium. Los tragúlidos o ciervos de agua son pequeños rumiantes que en la actualidad habitan los bosques tropicales de África y Extremo Oriente. Otro rumiante característico fue Eotragus, el primer bóvido que aparece en el registro europeo. Eotragus apenas sobrepasaba los $50 \mathrm{~cm}$ de altura hasta la cruz y mostraba unas pequeñas astas rectilíneas en su cabeza, muy lejos de la corpulencia y robustez que muestran los actuales toros y búfalos. Bien diferente es el caso de Ampelomeryx, otro rumiante de la fauna de Els Casots, perteneciente a la familia de los paleomerícidos. Ampelomeryx se caracterizaba por presentar tres apéndices craneales sobre la cabeza: dos sobre las órbitas oculares, como las actuales jirafas, más otro mucho más aparatoso que salía de la nuca y se bifurcaba formando una figura en "Y" griega.

Aparte de estos herbívoros de porte grácil, otros herbívoros de gran talla, como los rinocerontes acuáticos del género Brachypotherium, frecuentaban el antiguo lago de Els Casots. Brachypotherium carecía de los apéndices córneos que hoy caracterizan a los rinocerontes y llevaba un tipo de vida semianfibio, semejante al que actualmente llevan los hipopótamos. Sus patas eran cortas y debía pasar buena parte de su vida en el agua.

Entre los carnívoros hacen su aparición por primera vez los úrsidos, representados por el género Hemicyon. Curiosamente Hemicyon era muy diferente de los osos actuales. De talla grande (un metro y medio de longitud), su cuerpo no era robusto y pesado sino más bien ligero, como el de cualquier otro carnívoro. Además, a diferencia de los osos actuales, no era plantígrado sino digitígrado, es decir, se apoyaba únicamente sobre sus dedos, como hace un lobo o una pantera. Ello indica que Hemicyon debía de ser un cazador activo y un buen corredor, que tal vez practicase la caza cooperativa.

Así mismo, es al final del Mioceno inferior que se produce en Europa la entrada de los primeros primates catarrinos, representados por el género 


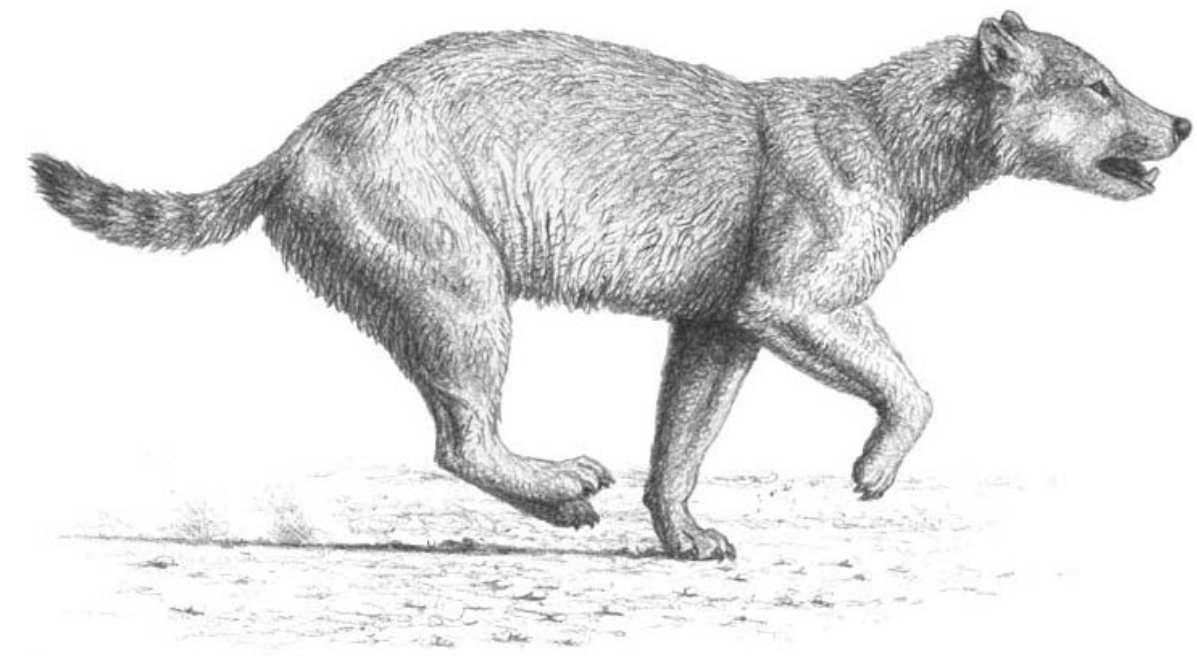

Pliopithecus, un pequeño simio de brazos largos cuyo modo de vida sería semejante al de los actuales gibones.

\section{EL ARAGONIENSE MEDIO (ENTRE 16 Y 14 MILLONES DE AÑOS)}

El Aragoniense medio está sobre todo representado en las cuencas de Calatayud-Daroca (Valdemoros) (ALCALÁ; MORALES; SORIA, 1990), Tajo (Puente de Vallecas, Torrijos, La Hidroeléctrica, Moratines, La Retama) (MORALES; ALCALÁ; HOYOS, 1993) y Ebro (Tarazona) (ASTIBIA, 1987). Las faunas de micromamíferos de estas localidades muestran pocas variaciones respecto a la del Aragoniense inferior, compuestas por una variada gama de cricétidos y glíridos (DAAMS; FREUDENTHAL; VAN DER WEERD, 1977). Dentro de esta última familia cabe destacar la proliferación de Armantomys, un género caracterizado por la posesión de molares simples y de corona alta, probablemente adaptados a la ingestión de vegetación coriácea. $Y$ es que el tránsito del Mioceno inferior al Mioceno medio, hace unos 15 millones de años, marcó un profundo cambio ambiental en la Península Ibérica. De un biotopo húmedo y boscoso, como el que evidencian las faunas del Vallès-Penedès del tipo de Els Casots, con una alta diversidad de especies, se pasó a un biotopo mucho más seco y abierto. En este contexto, la fauna de mamíferos estaba dominada por grandes herbívoros adaptados a una dieta basada en vegetación coriácea.

Los cérvidos quedaron reducidos en la práctica a la especie Procervulus dichotomus. Por el contrario, los paleomerícidos se convierten en los rumiantes dominantes, sobresaliendo la especie Triceromeryx pachecoi. A diferen- 
cia de Ampelomeryx del Mioceno inferior, Triceromeryx presentaba sobre las órbitas unos pequeños apéndices rectilíneos mientras que el apéndice occipital en forma de "Y" griega era mucho más reducido. Desaparecen los suidos de talla pequeña, quedando este grupo reducido a la especie Bunolistriodon lockharti, de la talla de un jabalí grande. Como único elemento asociado a cursos de agua estables, persisten en esta época los ciervos de agua del género Dorcatherium. Pero el elemento más característico de estas faunas del Mioceno medio ibérico fue sin duda un pequeño rinoceronte, Hispanotherium, así bautizado por el paleontólogo español Royo y Gómez en la localidad madrileña de Puente de Vallecas. Hispanotherium difería de sus parientes semiacuáticos del Mioceno inferior por diversas características que indican su adaptación a un biotopo de tipo pradera. En primer lugar, sus patas eran relativamente más largas y gráciles, adaptadas por tanto a la carrera en un medio abierto. Pero es que, además, sus dientes habían incrementado notablemente su altura (dentición hipsodonta), al tiempo que el esmalte se replegaba, formando entrantes y salientes que a su vez eran rellenados por cemento dentario. Todo ello nos indica que Hispanotherium se nutría de vegetales duros, tal vez gramíneas, que es el tipo de vegetación dominante en ambientes de tipo sabana o de pradera. La aparición de Hispanotherium en el Mioceno medio ibérico plantea una interesante problemática zoogeográfica, ya que este género se ha encontrado también en el Mioceno de Turquía y Asia pero falta en el resto de Europa y en África. Hay que suponer, por tanto, que durante el Mioceno medio se estableció una vía de comunicación directa entre la Península Ibérica y Asia menor, independientemente de la tradicional vía de comunicación a través de los Pirineos.

\section{EL ARAGONIENSE SUPERIOR (ENTRE 14 Y 11 MILLONES DE AÑOS)}

El Aragoniense superior se encuentra representado en las cuencas de Calatayud-Daroca (Manchones, Arroyo de Val) (FREUDENTHAL, 1966), Tajo (Paracuellos 3, Henares 1) ( ALCALÁ; MORALES; SORIA, 1990) y Duero (Cerro del Otero, Escobosa) (AZANZA; MENÉNDEZ, 1980), pero es sobre todo en la cuenca del Vallès-Penedès en donde se encuentra una secuencia más completa de esta parte del Aragoniense incluyendo yacimientos como Sant Quirze, Castell de Barberà, Can Missert y todos aquellos incluidos en la secuencia de Hostalets de Pierola (Can Mata 1, Can Mata 3, Abocador de Can Mata y otros) (AGUSTí; CABRERA; MOYÀ-SOLÀ, 1985; CASANOVASVILAR; MADERN; ALBA et ál., 2016).

El final del Mioceno medio, hace unos 12 millones de años, marca en la Península Ibérica el retorno al biotopo húmedo y boscoso que caracterizara el Mioceno inferior. Prueba de ello son los numerosos restos de castores que aparecen en los yacimientos de esta edad de la cuenca del Vallès-Penedès. 
Entre ellos, el género Palaeomys mostraba unas características semejantes a la del actual castor centroeuropeo, siendo el mayor roedor que aparece en estos yacimientos. Sin embargo, junto a Palaeomys se encuentra también un castor de talla pequeña, Euroxenomys, más frecuente que el anterior y cuyo modo de vida debió ser parecido al de las actuales ratas de agua. Las copas de los árboles eran surcadas por diversas especies de ardillas voladoras o esciurópteros, como las que actualmente pueblan los bosques del sudeste asiático. A su vez, se encuentra una variada gama de pequeños roedores compuesta por cricétidos (Hispanomys, Eumyarion, Anomalomys, Megacricetodon, Fahlbuschia y otros), glíridos (Eomuscardinus, Myoglis, Miodyromys, Bransatoglis y otros) y eómidos (Eomiops, Keramidomys).

Los paleomerícidos han sido reemplazados por una gran profusión de ciervos de diverso tipo (AZANZA; MENÉNDEZ, 1980). Algunos eran de pequeñas dimensiones y sin astas, como Micromeryx. Otros, en cambio, presentaban astas, aunque no tan desarrolladas como las de los ciervos que hoy pueblan Europa. Algunos de ellos, como Heteroprox, mostraban todavía astas muy primitivas, similares a las de los ciervos del Mioceno inferior como Procervulus y consistentes en un único candil principal débilmente bifurcado en su extremo. Las astas de Heteroprox, como las de Procervulus, eran perennes, es decir, no existía la típica roseta a partir de la cual en los ciervos actuales el asta se desprende cada año para crecer al siguiente. A partir de la parte más reciente del Mioceno medio, Heteroprox es habitualmente substituido en los yacimientos de esta edad por otros ciervos con astas caedizas como Euprox o Palaeoplatyceros. El diseño del asta en Euprox es todavía muy simple, formado por un corto pedículo coronado en su extremo por dos candiles de talla diferente. También abundan los ciervos de agua como Dorcatherium. Al mismo tiempo, los suidos vuelven a ser elementos dominantes en los bosques de finales del Mioceno medio. Una variada gama de formas parecidas a los actuales jabalíes y pécaris aparecen en yacimientos como Sant Quirze y Castell de Barberà, en la cuenca del Vallès-Penedès: Barberahyus (un pequeño pécari), Conohyus (un suido de premolares alargados), Parachleuastochoerus (un enano en su grupo), Korinochoerus (un pariente cercano de los actuales jabalíes y cerdos) y Listriodon (VAN DER MADE, 1990). De todos ellos, el elemento más común en las faunas de esta edad es, con diferencia, Listriodon, que alcanzaba la talla de un gran jabalí y se diferenciaba de sus parientes actuales sobre todo por su dentición. En efecto, la mayor parte de suidos (incluido el jabalí y su variante doméstica, el cerdo) tienen unos molares de tipo bunodonto, es decir, formados por cúspides aisladas que muelen el alimento al ocluir entre sí. Este patrón dentario es típico de una dieta muy amplia, de tipo omnívoro, que puede incluir tanto restos vegetales como animales. Este es el caso de la mayor parte de géneros citados anteriormente, pero no el de Listriodon, que presentaba unos molares formados por dos crestas transversales y adaptado, por tanto, a una dieta basada en vegetales duros. Sus incisivos habían adoptado una forma 
muy peculiar, con la corona muy corta y ensanchada, en forma de paleta, igualmente adaptados a extirpar vegetación arbustiva a ras de suelo. Los machos tenían dos grandes colmillos recurvados hacia arriba.

A su vez, los grandes proboscídeos como Deinotherium siguen estando presentes, acompañados por gonfoterios del género Tetralophodon (más grandes que su pariente Gomphotherium). Por su parte, los rinocerontes acuáticos y de bosque vuelven a ser dominantes, substituyendo a las formas corredoras del tipo de Hispanotherium. Entre ellos destaca Hoploaceratherium, un rinoceronte muy frecuente en numerosos yacimientos del Mioceno ibérico. En realidad, tanto por su aspecto como por su modo de vida Hoploaceratherium difícilmente encaja dentro del concepto que hoy tenemos de un rinoceronte. Para empezar, Hoploaceratherium carecía de los característicos apéndices córneos que han hecho famoso a este grupo de perisodáctilos. Además, el morro de Hoploaceratherium estaba coronado por unos grandes incisivos que le servían para arrancar la abundante vegetación acuática de que se alimentaba. Un perisodáctilo particularmente frecuente en los yacimientos de esta edad es Anisodon, perteneciente a la familia de los calicotéridos. Los calicotéridos eran perisodáctilos emparentados con el grupo de los caballos y rinocerontes. Sin embargo, los representantes de esta familia, y Anisodon entre ellos, presentaban una anatomía muy diferente de la de sus parientes. Las extremidades anteriores eran más largas que las posteriores y, en lugar de pezuñas, estaban dotados de garras. Se piensa que estos lejanos parientes del caballo eran, probablemente, ramoneadores de árboles y arbustos, cuyas hojas debían agarrar con sus "manos", adoptando una postura que más recordaría a la de los actuales gorilas que a la de un équido. Esta variada fauna de grandes herbívoros hallaba su contrapunto entre los grandes depredadores como Sansanosmilus, de la familia de los barbourofélidos. La característica más relevante de este grupo de carnívoros eran sus largos colmillos ("dientes de sable"), que alojaban en una expansión de la mandíbula que les hacía de estuche. Sansanosmilus fue el superdepredador habitual de los yacimientos del Mioceno medio de Europa.

Pero uno de los elementos más significativos de estas faunas de finales del Mioceno medio son los primates. En este sentido cabe destacar el extraordinario registro de este grupo procedente de la sección de Hostalets de Pierola, en la subcuenca del Penedès, $y$, más concretamente, de la serie conocida con Abocador de Can Mata. En esta serie se han encontrado diversos restos craneales y post-craneales de diversos hominoideos pertenecientes a los géneros Dryopithecus, Anoiapithecus y Pierolapithecus. En particular destaca un esqueleto muy completo de la especie Pierolapithecus catalaunicus, que ha permitido aclarar aspectos muy significativos de los primeros hominoideos antropomorfos (ALBA, 2012). Junto a ellos destaca también un pequeño primate, Pliobates, relacionado con el género Pliopithecus y que tal vez esté en el origen de los actuales gibones.
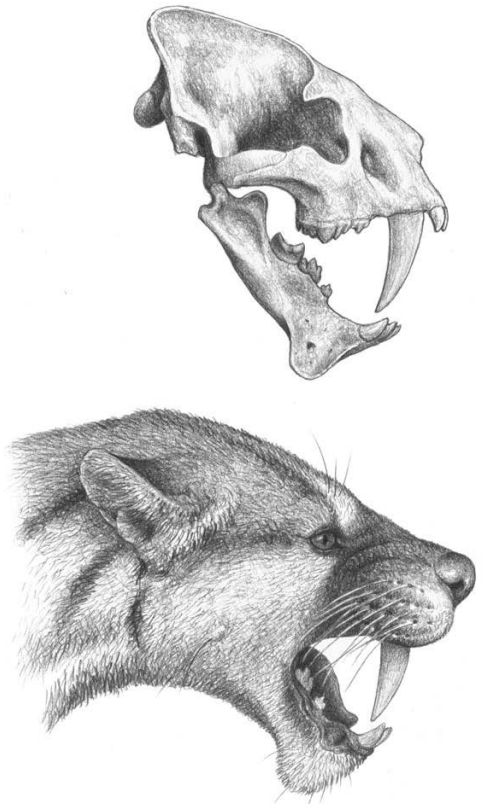

Cráneo y reconstrucción de Sansanosmilus 


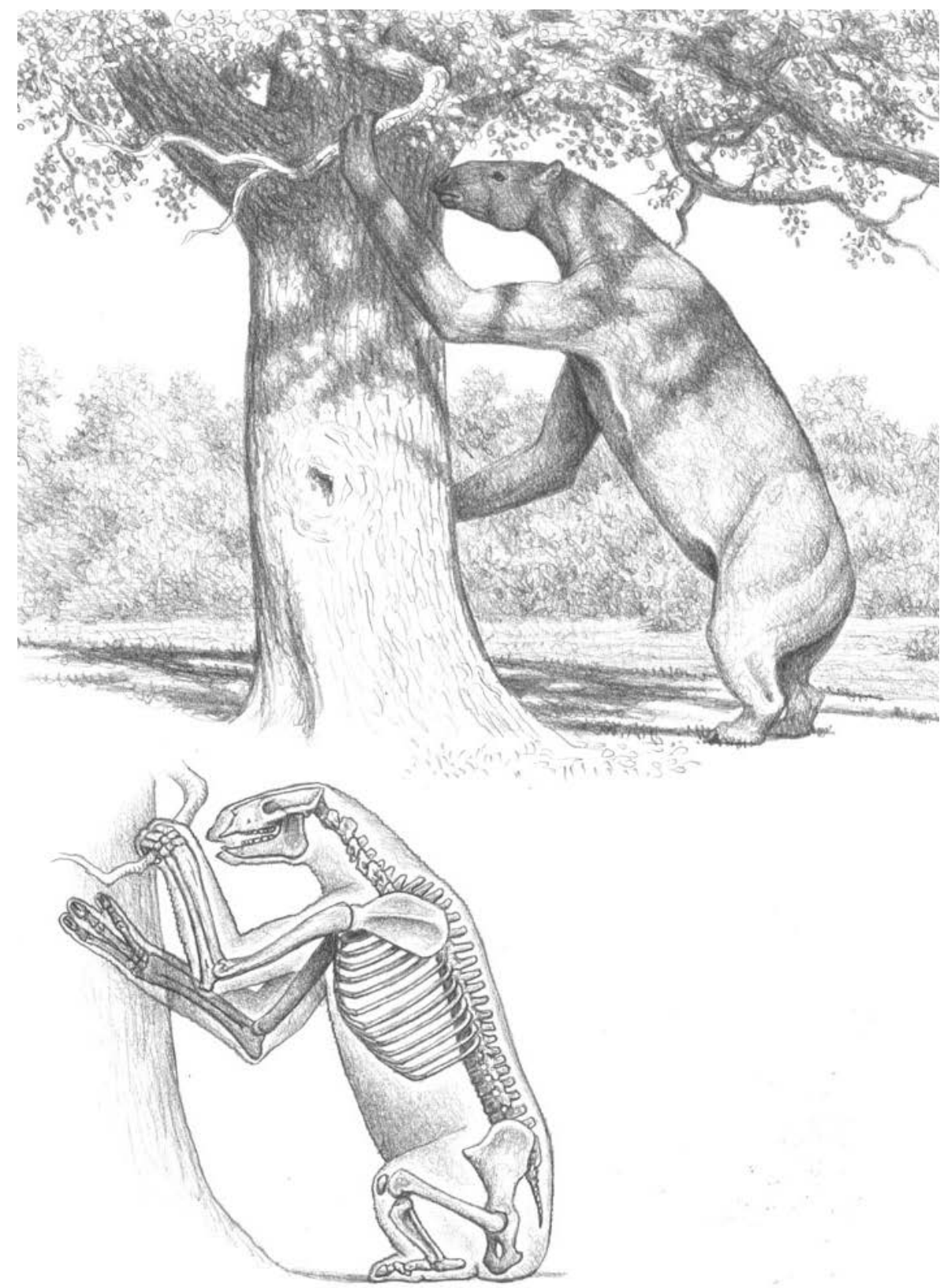

Esqueleto y reconstrucción de Anisodon

\section{EL VALLESIENSE (ENTRE 11 Y 8,7 MILLONES DE AÑOS)}

Al inicio del Mioceno superior, hace unos 10 millones de años, se produjo un nuevo descenso del nivel del mar a nivel global. Los océanos descendieron cerca de 100 metros, de manera que nuevos puentes intercontinentales emergieron, permitiendo la migración y el intercambio entre las faunas terrestres. Este fue el caso de Hippotherium (anteriormente incluido en el 
supergénero Hipparion), un pequeño caballo de tres dedos, originado en América del Norte hace unos 15 millones de años y que, como su pariente Anchitherium cinco millones de años antes, se expandió rápidamente por Europa y Asia (GARCÉS; CABRERA; AGUSTí, 1997). En su migración, las primeras oleadas de hipariones arrastraron consigo a otros grandes mamíferos de origen asiático que acompañaron a estos équidos en su viaje hacia Europa (AGUSTí; ANTÓN, 1992). Tal es el caso de Machairodus, un felino del tamaño de un léon que se distinguía por el gran tamaño de sus colmillos, lo que le ha valido la denominación popular de "tigre dientes de sable". Junto a ellos, se encontraban también los primeros jiráfidos que entraron en Europa, encuadrados dentro de los géneros Palaeotragus y Decennatherium. Decennatherium tenía la talla de un okapi y pertenecía al grupo de los sivaterinos. Los sivaterinos no presentaban los largos cuellos que hoy ostentan las jirafas actuales y así mismo sus extremidades eran más cortas. Se caracterizaban por presentar no uno sino dos pares de apéndices craneales. Los primeros, pequeños y cónicos, estaban situados sobre las órbitas y recuerdan los que hoy podemos ver en las jirafas y el okapi. Los segundos, en posición más retrasada, eran mucho más grandes y de forma aplanada, expandiéndose lateralmente.

Faunas de este tipo, a base de hipariones, jiráfidos y grandes félidos "dientes de sable" eran conocidas desde principios del siglo XX en Grecia, en las localidades de Pikermi y Samos. En España, era también conocida la localidad de Concud (Teruel). En todas estas localidades, las faunas del Mioceno superior, compuestas básicamente por hipariones, jirafas, antílopes y felinos "dientes de sable", habían sustituido a aquellas otras del Mioceno medio compuestas mayoritariamente por ciervos, suidos, rinocerontes y grandes cánidos como Amphicyon. Sin embargo, cuando los paleontólogos Miquel Crusafont, Josep F. de Villalta y Jaume Truyols iniciaron sus investigaciones en la cuenca del Vallès-Penedès, se encontraron con un curioso problema paleontológico. Así, los hipariones constituían un elemento muy frecuente en numerosos yacimientos de esta cuenca como Can Ponsic, Can Llobateras, Viladecavalls o los niveles más superiores de la serie de Hostalets de Pierola. No obstante, a diferencia de los que ocurría en Pikermi, Samos o Concud, la asociación que acompañaba estos équidos y a sus acompañantes como Machairodus era todavía idéntica a las del Mioceno medio, con abundancia de ciervos como Euprox y Micromeryx, ciervos de agua como Dorcatherium, suidos como Listridon, calicotéridos y otros. Crusafont advirtió que esta diferente composición faunística de las "faunas con Hipparion" del VallèsPenedès no se debía a una singularidad biogeográfica de esta cuenca, sino que correspondía a una etapa especial de la historia de nuestro continente que hasta entonces había pasado desapercibida (CRUSAFONT, 1950). Este autor propuso el piso "Vallesiense" para designar este tipo de faunas (por ser el Vallès una de las primeras cuencas donde había sido reconocido), con estratotipo en el yacimiento de Can Llobateres. 
El Vallesiense cuenta con un excelente registro en la Península Ibérica. Además de la cuenca del Vallès-Penedès (AGUSTí; CABRERA; MOYÀSOLÀ, 1985; CASANOVAS-VILAR; MADERN; ALBA et ál., 2016), este piso mastológico se encuentra ampliamente representado en las cuencas de Calatayud-Daroca (Nombrevilla, Pedregueras) (FREUDENTHAL, 1968), Teruel (Masía del Barbo) (ALBERDI; MORALES, 1981), Duero (Los Valles de Fuentidueña) (ALBERDI; LÓPEZ; MORALES, 1981) y Tajo (Cerro Batallones) (MORALES; POZO; SILVA et ál., 2008). También se han registrado niveles vallesienses en las cuencas pirenaicas de la Cerdaña y la Seu d'Urgell (AGUSTÍ; GIBERT; MOYÀ-SOLÀ et ál., 1979; AGUSTí; ROCA, 1987), así como en la cuenca de Guadix-Baza (Cortijo de la Piedra) (MARTÍN-SUÁREZ; GARCÍA-ALIX; MINWER-BARAKAT et ál., 2012). Pero es sin duda en la cuenca del Vallès-Penedès donde se encuentra un registro más completo de este piso mastológico. Dentro del Vallesiense puede diferenciarse un Vallesiense inferior y un Vallesiense superior. El Vallesiense inferior está representado en la cuenca del Vallès-Penedès por una serie de yacimientos que presentan una extraordinaria diversidad tanto de macromamíferos como de micromamíferos. Es el caso, especialmente, del yacimiento de Can Llobateres, que ha librado más 60 especies.

La asociación de mamíferos de Can Llobateres muestra la característica mezcla de elementos típicos del Mioceno medio junto a los nuevos invasores asiáticos y americanos del Vallesiense. Así, el équido Hippotherium aparece asociado a una fauna de herbívoros que es intercambiable con la de yacimientos como el de Sant Quirze. Entre los rinocerontes se encuentran los sin cuernos del género Aceratherium (de características semejantes a Hoploaceratherium), junto a otros que muestran los típicos apéndices córneos como Lartetotherium o Dihoplus, un rinoceronte de gran talla. Entre los proboscídeos, persisten los gonfoterios del género Tetralophodon así como Deinotherium, representado por Deinotherium laevius, una especie de gran-

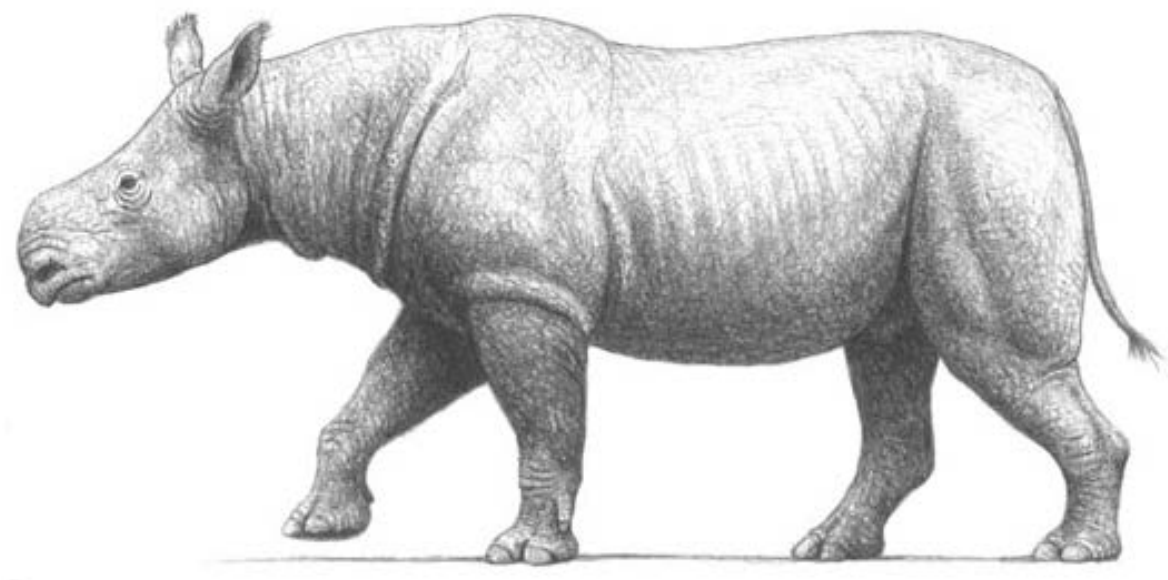


des dimensiones. Como en faunas anteriores, abundan los suidos y los cérvidos. Lo curioso es que todos estos elementos persistentes coexisten durante el Vallesiense con sus teóricos competidores de procedencia oriental. Así, los jiráfidos del género Decennatherium presentes en Can Llobateres y otras localidades vallesienses aparecen asociados a la fauna de ciervos que encontrábamos en Sant Quirze: Micromeryx, Euprox, Dorcatherium y otros.

Entre los grandes carnívoros, los primeros "dientes de sable" del género Machairodus coexistirán con los últimos Sansanosmilus de la arcaica familia de los barburoufélidos. En el nicho ecológico de tipo "oso", los primeros úrsidos de porte moderno de los géneros Indarctos y Ursavus coincidirán con los grandes "perros-osos" como Amphicyon. También en esta época encontramos las primeras hienas como Thalassictis y Protictitherium, todavía muy parecidas a sus parientes los vivérridos. La presencia de tapires (Tapirus priscus), ardillas voladoras (géneros Albanensia y Miopetaurista), castores (géneros Chalicomys y Euroxenomys) testimonia la presencia de un bosque húmedo en el Vallesiense inferior del Vallès-Penedès. Entre los micromamíferos, el transito del Aragoniense superior al Vallesiense inferior no comportará en principio grandes cambios en la fauna de roedores, todavía dominada por una profusión de cricétidos, glíridos y eómydos.

Elementos destacados de las faunas del Vallesiense inferior del VallèsPenedès son los hominoides del género Hispanopithecus. Este género fue inicialmente reconocido por Crusafont y Villalta en base a restos mandibulares y dentarios. Sin embargo, hasta el año 1993 poco era lo que se sabía de su anatomía craneal y post-craneal. Las cosas cambiaron en ese año cuando en el yacimiento de Can Llobateres apareció un fragmento craneal muy completo que mostraba cómo era la cara de Hispanopithecus . En excavaciones posteriores, no tan solo la cara sino buena parte del esqueleto de Hispanopithecus salió finalmente a la luz (MOYA-SOLA; KOHLER, 1996). La sorpresa, sin embargo, fue notable, al observarse que Hispanopithecus mostraba unas afinidades mucho más estrechas con el orangután asiático que con los grandes antropomorfos africanos. El esqueleto de Hispanopithecus también era mucho más parecido al de un orangután, mostrando unos brazos y manos desproporcionadamente largos. A diferencia, pues, de chimpancé y gorila, Hispanopithecus raramente descendía al suelo, haciendo una vida básicamente arborícola. La presencia de Hispanopithecus y ardillas voladoras testimonia la existencia de un bosque de tipo subtropical húmedo en las inmediaciones de Can Llobateras hace unos 10 millones de años.

El tránsito al Vallesiense superior, sin embargo, comportó un significativo cambio en las condiciones climáticas y ambientales que conllevó la desaparición de buena parte de los elementos predominantes durante el Mioceno (AGUSTí; MOYA-SOLA, 1990; AGUSTÍ; SANZ DE SIRIA; GARCÉS, 2003). En este contexto, las formas típicas de bosque húmedo, como los suidos y los

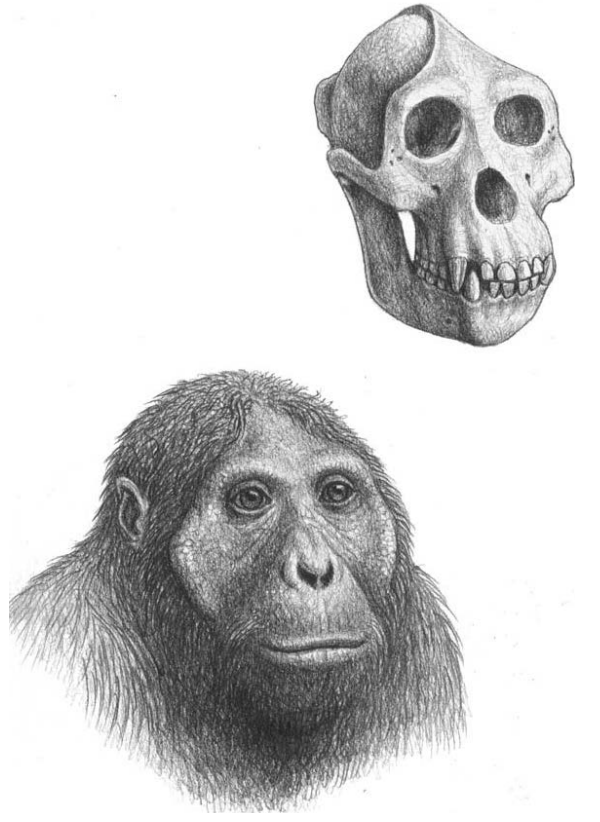

Reconstrucción de Hispanopithecus 


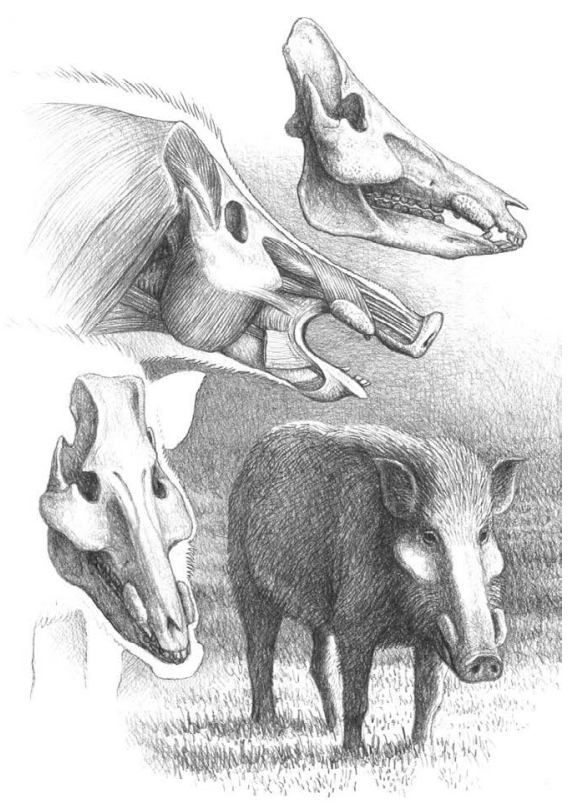

Cráneo y reconstrucción de Microstonyx ciervos, se vieron especialmente afectadas por el cambio ambiental. Entre los suidos, desaparecieron los pécaris como Barberahyus y Taucanamo, el pequeño Parachleuastochoerus y el hasta entonces ubicuo Listriodon. Estos fueron sustituidos por Microstonyx, una especie de jabalí gigante que a partir de entonces se convirtió en el suido dominante. Los ciervos como Euprox y Micromeryx se vieron súbitamente diezmados, y otro tanto se observa entre los ciervos de agua del género Dorcatherium. Con ellos, los últimos restos de Hispanopithecus se encuentran todavía en algunos yacimientos del Vallesiense superior. Entre los carnívoros, desaparecen definitivamente los anficiónidos y los hiénidos primitivos. Por primera vez aparecen hienas de aspecto moderno como Adcrocuta. Adcrocuta eximia era mucho más robusta que sus parientes vallesienses Thalassictis y Protictitherium y mostraba ya la típica especialización dentaria que le permitía triturar y deglutir los huesos de las carroñas. En definitiva, la crisis climática del Vallesiense superior alcanzó también a la variada fauna de roedores que hasta entonces había poblado los bosques vallesienses. Las formas arborícolas como las ardillas voladoras, o las formas asociadas a cursos de agua, como los grandes castores del género Chalicomys, desaparecen abruptamente del registro fósil. Este es también el caso de numerosos elementos de la variada fauna de cricétidos, glíridos y eómidos del Aragoniense superior y del Vallesiense inferior. De entre los glíridos, sólo unos pocos supervivientes superarán la crisis del Vallesiense superior, quedando reducidos prácticamente a los géneros que todavía hoy pueblan Europa, como es el caso de Glis, Muscardinus, Glirulus o Myomimus. Los cricétidos también se verán severamente afectados por esta crisis, desapareciendo buena parte de los géneros que habían poblado Europa durante el Mioceno, como Democricetodon, Megacricetodon o Eumyarion. Sólo aquellos cricétidos que mostraban una dentición adaptada a la ingestión de vegetales duros, como Hispanomys o Rotundomys, se verán beneficiados por las nuevas condiciones. Los eómydos desaparecen prácticamente del registro ibérico y buena parte del europeo. Es en este momento cuando hacen su aparición en Europa occidental los primeros múridos del género Progonomys, la familia que incluye a ratas y ratones. De origen asiático, a partir del Vallesiense superior, los múridos se convertirán en los elementos dominantes de las faunas de roedores.

\section{EL TUROLIENSE (ENTRE 8,7 Y 7 MILLONES DE AÑOS)}

Tras la crisis del Vallesiense superior, un nuevo tipo de fauna de mamíferos se instala en la Península Ibérica, dominado por hiénidos carroñeros y grandes herbívoros corredores (équidos, bóvidos y jiráfidos), adaptados a las praderas herbáceas. Este periodo de tiempo está muy bien representado en la cuenca de Teruel, razón por la cual el paleontólogo Miquel Crusafont propuso el nombre de Turoliense para designarlo. Aparte del yacimiento de Los Mansuetos, estratotipo de este piso mastológico, cabe reseñar los 
yacimientos de Los Aguanaces, Concud, Rambla de Valdecebro y Los Algezares (ALCALÁ, 1994). Más allá de la cuenca de Teruel, el Turoliense se encuentra representado en las cuencas del Vallès-Penedès (Piera) (AGUSTÍ; CABRERA; MOYÀ-SOLÀ, 1985; SANTAFÉ; CASANOVAS, 1982), Crevillente (Crevillente 2) (ALCALÁ; MONTOYA, 1990) y Fortuna, en Murcia (Casa del Acero) (AGUSTí; GIBERT; MOYÀ-SOLÀ, 1981; AGUSTí, 1986).

Durante el Turoliense, la diversidad de cérvidos y suidos se ve drásticamente reducida. Entre los cérvidos encontramos tan sólo los géneros Lucentia y Procapreolus. Aunque de diseño simple, las astas de estos cérvidos muestran ya la presencia de un candil que anuncia la estructura posterior de las astas de los ciervos modernos (AZANZA; MENÉNDEZ, 1990). Los suidos se encuentran representados básicamente por Microstonyx, que incrementa incluso su talla con respecto a los representantes del Vallesiense superior.

Desde ese momento, las comunidades de artiodáctilos pasan a estar dominadas por bóvidos y jiráfidos corredores. Entre los bóvidos, hasta entonces muy escasos en yacimientos del Vallesiense, se hace extraordinariamente abundante el género Tragoportax, que pertenece al grupo de los boselafinos, que en la actualidad están representados por el nilgo (Boselaphus tragocamelus), un gran antílope de las altas praderas de la India. También por esta época aparecen las gacelas, un elemento muy común en las faunas europeas de finales del Mioceno y que desaparecerá de este continente con la llegada de los primeros fríos del Cuaternario. Otros elementos comunes en las faunas del Turoliense son los jiráfidos, representados por el género Birgerbohlinia, un pariente próximo del género vallesiense Decennatherium, aunque de talla más grande y constituye la prolongación de este grupo en el Turoliense.

El grupo de los hipariones será otro de los beneficiados por el cambio ambiental, convirtiéndose en uno de los elementos más abundantes de esta época, representados por la especie Hipparion concudense. Por lo que respecta al resto de perisodáctilos, la diversidad de rinocerontes decrece, representados ahora por los supervivientes Aceratherium incisivum y el gran Dihoplus scheleirmarcheri. Entre los calicotéridos, persisten los representantes del género Anisodon, aunque su presencia se hace cada vez más rara en los yacimientos turolienses. Entre los proboscídeos, los gonfoterios del género Tetralophodon desaparecen de escena. Por su parte, los últimos dinoterios todavía se encuentran presentes en los niveles más bajos del Turoliense, como es el caso del yacimiento de Piera, desapareciendo poco después del registro ibérico.

Entre los roedores, los múridos se hacen ahora dominantes, representados por los géneros Parapodemus, Occitanomys y Huerzelerimys (MEIN; MARTíNSUÁREZ; AGUSTÍ, 1993). Los cricétidos están básicamente representados

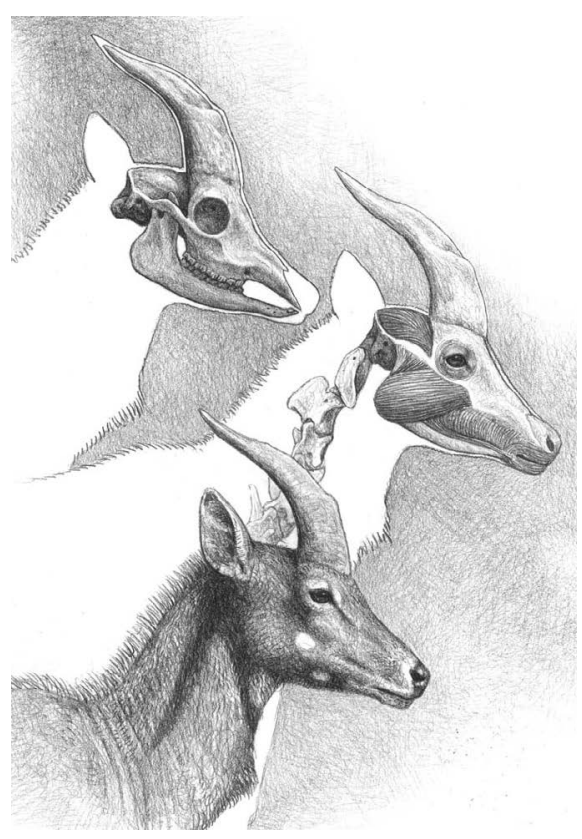

Cráneo y reconstrucción de Tragoportax 
por formas con dientes de corona cada vez más alta (Ruscinomys, un descendiente de Hispanomys) y por los precursores de los hámsteres modernos (Neocricetodon). Entre los glíridos, el lirón Eliomys truci, antecesor del actual lirón careto, es la única especie presente en las asociaciones del Turoliense. Los castóridos están tan sólo representados por el pequeño castor Dipoides.

Entre los carnívoros, persisten los hiénidos carroñeros de corte moderno del género Adcrocuta, junto a otros hiénidos corredores de porte grácil como Talassictis o Plioviverrops. Entre los "dientes de sable", dominan las formas de talla moderada, como Promegantereon, de la talla de un leopardo, o como Stenailurus y Metailurus, cuyos caninos no excedían el tamaño de los de un felino moderno. Los úrsidos están representados por formas robustas de grandes dimensiones como Indarctos y Agriotherium. Cabe destacar en este momento la irrupción del primer cánido precursor de los actuales lobos y perros, apodado Canis cipio por Crusafont, y que se encuentra en los yacimientos de Concud y Los Mansuetos. Esta especie se encuadra actualmente dentro del género Eucyon, una forma precursora del género Canis.

\section{EL VENTIENSE (ENTRE 7 Y 5 MILLONES DE AÑOS)}

Frente a los grandes espacios abiertos típicos del Turoliense, con su cohorte de antílopes, jiráfidos e hipariones, las faunas de mamíferos de la parte final del Mioceno en la Península Ibérica muestran un notable incremento de diversidad, así como la reaparición de algunos grupos que indican un ambiente más húmedo y forestado. Así, de nuevo aparecen formas de bosque como los ciervos de tipo moderno, con astas con varios candiles, como Croizetoceros. La abundancia de cursos de agua permanentes queda de manifiesto por la reaparición de los cocodrilos y por la entrada de los primeros hipopótamos. Aparecen los primeros bóvidos de porte pesado como Parabos, precursores de lo que luego serán los búfalos y bisontes. Este tipo de faunas había sido asimilado a la parte más alta de Turoliense, pero en 1984 el paleontólogo del Museo Nacional de Ciencias Naturales en Madrid Jorge Morales propuso separar las faunas de finales del Mioceno de las del Turoliense típico, proponiendo un nuevo piso mastológico, el Ventiense, con estratotipo en el yacimiento de Venta del Moro, en la cuenca del Cabriel, cuyo estudio fue el objeto de su tesis doctoral (Morales, 1984). Aparte la localidad-tipo de Venta del Moro, el Ventiense se encuentra representado en las cuencas de Teruel (El Arquillo) (ALCALÁ, 1994), Fortuna (Librilla, Romerales y otros) (AGUSTí; LLENAS, 1996; VAN DER MADE; MORALES, 1999) y Granada (Arenas del Rey, Purcal y otros) (MARTÍN-SUÁREZ; OMS; FREUDENTHAL et ál., 1998; GARCíA-ALIX; MINWER-BARAKAT; MARTÍN et ál., 2008).

Las faunas del Ventiense vienen marcadas por el extraordinario evento conocido como "Crisis de Salinidad del Messiniense". Hace unos 6 millo- 
nes de años, se produjo el cierre por razones tectónicas del estrecho rifeño, única vía de comunicación que quedaba entre el Océano Atlántico y el Mar Mediterráneo, tras el cierre anterior del estrecho bético, la otra vía de comunicación existente hasta entonces. Como consecuencia, el Mediterráneo se desecó casi completamente, quedando reducido a unos grandes lagos salinos. La desecación del mar Mediterráneo durante el Messiniense abrió nuevos puentes continentales de comunicación entre las faunas terrestres de Europa, África y Asia. En el caso de la Península Ibérica, los efectos de la desecación del Mediterráneo se hicieron mucho más patentes, ya que permitieron la entrada de elementos africanos a través de la zona bética. Así, entre las faunas de roedores de esta edad, se encuentran por primera vez representantes de la familia de los gerbílidos (AGUSTí, 1990; AGUSTÍ; CASANOVAS-VILAR, 2003). Los gerbílidos son roedores africanos que en la actualidad pueblan las zonas desérticas y subdesérticas del norte de África. En yacimientos como el de Salobreña, en Granada, y Almenara, en Castellón, los gerbílidos de los géneros Debruijnimys y Myocricetodon constituyen más del $50 \%$ de la fauna de roedores. Este tipo de faunas con roedores de origen africano se encuentran también en la cuenca Guadix-Baza, en la serie del Negratín (MINWER-BARAKAT; GARCíA-ALIX; AGUSTÍ et ál., 2009). Por lo demás, el resto de la fauna de roedores sigue dominada por los múridos, que incluso incrementan su diversidad. A los pre-existentes Occitanomys y Apodemus, se unen ahora los géneros Stephanomys y Paraethomys, este último de probable origen africano.

Entre los nuevos inmigrantes africanos del Messiniense también se encuentran mamíferos acuáticos como los pequeños hipopótamos del género Hexaprotodon, que hasta entonces eran elementos desconocidos en el registro euroasiático (VAN DER MADE, 1990). Pero sin duda, uno de los elementos más sorprendentes que entran durante el Messiniense en la Península Iberica es Paracamelus, un típico representante de la familia de los camélidos. Paracamelus era un auténtico camello de gran talla, que presentaba ya muchas de las características típicas de este grupo. Su dentición era de corona alta, adaptada a la dura vegetación característica de los ambientes subdesérticos. Como en los camellos actuales, la pata presentaba dos únicos dedos. Estos dedos, a pesar de tener fusionados parcialmente metatarsianos y metacarpianos, tendían a estar muy separados entre sí, formando un ángulo muy abierto, lo que constituye una adaptación típica para la locomoción sobre substratos blandos. Paracamelus ha sido encontrado en los yacimientos del Ventiense en el Levante ibérico de Venta del Moro y Librilla (VAN DER MADE; MORALES et ál.,1999). A diferencia de otros inmigrantes del Messiniense, esta incursión de los camélidos en la Península Ibérica no tuvo mayores consecuencias, ya que Paracamelus no sobrepasó el límite entre los periodos Mioceno y Plioceno. Paracamelus coexistirá con formas persistentes del Turoliense, como los "antilopes" del género Tragoportax y con los primeros bóvidos de porte moderno del género Parabos, precur- 
sor de los actuales búfalos y bueyes. A diferencia de las formas corredoras como Tragoportax, las extremidades de Parabos eran más anchas y robustas, peor adaptadas a una marcha prolongada.

En cuanto a los équidos, durante Ventiense la diversidad dentro de los hipariones aumentó espectacularmente (ALBERDI; ALCALÁ, 1990), llegando a contabilizarse hasta tres especies de talla diferente coexisitiendo en el mismo yacimiento. Este es el caso de la localidad de El Arquillo, en Teruel, en donde, además de los hipariones robustos del tipo de Hippotherium concudense, se encuentra Cremohipparion gromovae, que no alcanzaba más de un metro hasta la cruz. La palma, sin embargo, se la llevaba el pequeño Hipparion periafricanum, del mismo yacimiento, cuya talla no excedía los 70 centímetros.

Los gonfoterios, raros durante el Turoliense, se hacen más abundantes en el Ventiense, representados por Anancus, un nuevo género que presenta características diferentes a los anteriores. Anancus arvernensis procede probablemente de alguna especie asiática de Tetralophodon, el género de gonfoterios dominantes durante el Vallesiense. Si bien la dentición era más o menos semejante a la del resto de gonfoterios, el cráneo de Anancus difería notablemente de sus predecesores. Así, en lugar de los cráneos alargados, típicos de Gomphotherium y Tetralophodon, el cráneo de Anancus era mucho más corto, de proporciones semejantes a las de los elefantes actuales. Paralelamente, la mandíbula es así mismo mucho más corta, habiendo perdido las dos defensas inferiores típicas de los gonfoterios del Mioceno medio. Por el contrario, las dos defensas superiores se hacen extraordinariamente largas y rectilíneas, llegando hasta los tres metros de longitud. Externamente, pues, Anancus debía parecerse más a un elefante moderno que a los gonfoterios que anteriormente habían poblado los bosques europeos, aunque sus extremidades eran comparativamente más cortas que las de los actuales proboscídeos. Con sus cerca de tres metros de altura, Anancus fue el herbívoro de mayor talla de las faunas de finales del Mioceno, persistiendo hasta hace unos 2 millones de años.

El Ventiense está caracterizado por una variada gama de carnívoros (ALCALÁ; MORALES; SORIA, 1990), que incluye el úrsido de grandes dimensiones Agriotherium y los felidos "dientes de sable" Amphimachairodus giganteus y Promegantereon maximiliani, de menores dimensiones. Entre los hiénidos persisten las hienas robustas del género Adcrocuta y las pequeñas hienas corredoras del género Thalassictis. Junto a ellos se encontraban los perros-mapache del género Nyctereutes. Todos estos elementos constituirán a su vez la base de las faunas de principios del Plioceno, tal como aparecen representadas en la localidad de Alcoy (Alicante).

En fin, hace unos 5 millones de años la erosión fluvial comenzó a actuar en la zona de Gibraltar. Los efectos progresivos de esta erosión llevaron al 


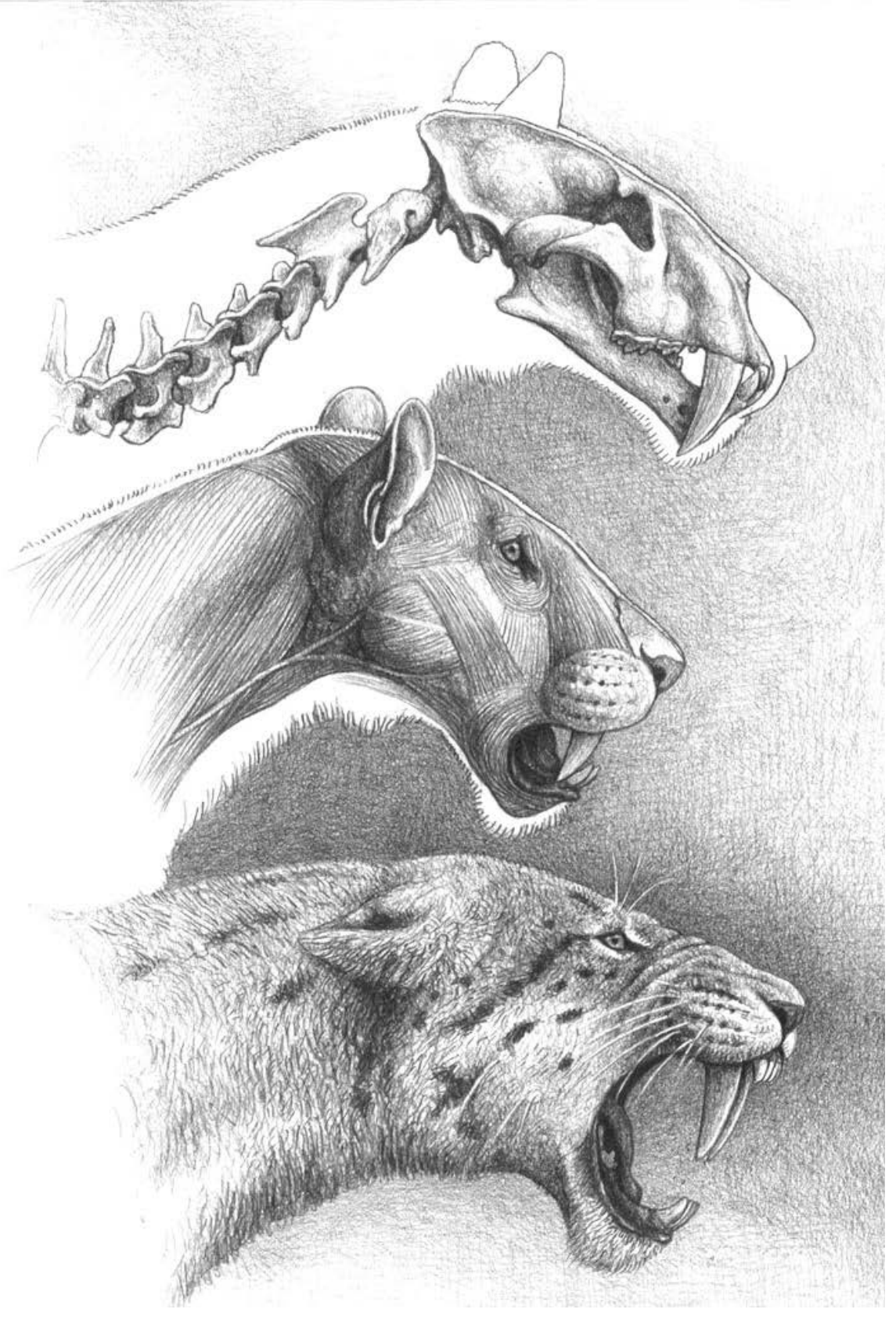

Cráneo y reconstrucción de Amphimachairodus

\section{Agradecimientos}

Quiero agradecer a Bienvenido MartínezNavarro la invitación a participar en este volumen. Así mismo, he de agradecer a Mauricio Antón la autorización para reproducir algunas de sus excelentes reconstrucciones de la fauna del Mioceno. Este capítulo se encuadra dentro de los proyectos CGL2016-80000-P (Ministerio de Economía y Competitividad, Spain) y SGR2017-859 (Gencat).

establecimiento del actual estrecho del mismo nombre, restableciéndose la comunicación con el Atlántico. Una gigantesca catarata abocó las aguas de este océano en la desecada cuenca del Mediterráneo, de manera que en pocos años el Mediterráneo adquirió su configuración actual. Había empezado el Plioceno. 


\section{BIBLIOGRAFÍA}

- AGUSTí, J. (1990) The Miocene Rodent Succession in Eastern Spain: a zoogeographical appraisal. En LINDSAY, E.; FAHLBUSCH, V.; MEIN, P. (ed.) European Neogene Mammal Chronology. New York: Plenum Press, 1990, pp. 375-404

- AGUSTí, J. (1986) Nouvelles espèces de cricetidés vicariantes dans le Turolien moyen de Fortuna (prov. Murcia, Espagne). Geobios, vol. 19, n. ${ }^{\circ}$ 1, 1986, pp. 5-11

- AGUSTÍ, J.; ANTÓN, M. (2002) Mammoths, sabertooths, and hominids. New York: Columbia University Press, 2002

- AGUSTÍ, J.; CABRERA, L.; MOYÀ-SOLÀ, S. (1985) Sinopsis estratigráfica del Neógeno de la fosa del Vallès Penedès. Paleontologia i Evolució, vol. 18, 195, pp. 57-84

- AGUSTÍ, J.; CASANOVAS-VILAR, I. (2003) Neogene gerbils from Europe. Deinsea, vol. 10, 2003, pp. 13-21

- AGUSTí, J.; GIBERT, J.; MOYÀ-SOLÀ, S. (1981) Casa del Acero: nueva fauna turoliense de Vertebrados (Mioceno superior de Fortuna, Murcia). Butlletí Informatiu de l'Institut de Paleontologia de Sabadell, vol. 13, n. ${ }^{\circ}$ 1-2, pp. 69-87

- AGUSTÍ, J.; GIBERT, J.; MOYÀ-SOLÀ; S.; CABRERA, L. (1979) Roedores e Insectívoros del Mioceno superior de Seu d'Urgell (Cataluña, España). Acta Geologica Hispanica, vol. 14, 1979, pp. 362-369

- AGUSTÍ, J.; LLENAS, M. (1993) Los roedores del Mioceno inferior de Els Casots (Vallès-Penedès). Nota preliminar. En GONZÁLEZ DONOSO, J. M. (ed.) Comunicaciones de las IX Jornadas de Paleontología; Málaga, 28-30 de octubre de 1993. [s.I.] : [s.n.], 1993, pp. 70-72

- AGUSTÍ, J.; LLENAS, M. (1996) The late Turolian muroid rodent succession in eastern Spain. Acta Zoologica Cracoviensia, vol. 39 (1), 1996, pp. 47-56

- AGUSTÍ, J.; MOYÀ-SOLÀ, S. (1990) Mammal extinctions in the Vallesian (Upper Miocene). Lecture Notes in Earth Science, vol. 30, 1990, pp. 425-432

- AGUSTÍ, J.; ROCA, E. (1987) Síntesis biostratigráfica de la fosa de la Cerdanya (Pirineos Orientales). Estudios Geológicos, vol. 43, 1987, pp. 521-529

- AGUSTÍ, J.; SANZ DE SIRIA, A.; GARCÉS, M. (2003) Explaining the end of the hominoid experiment in Europe. Journal of Human Evolution, vol. 45, 2003, pp. 145-153

- ALBA, D. M. (2012) Fossil Apes from the Vallès-Penedès Basin. Evolutionary Anthropology, 21, 2012, pp. 254-269

- ALBERDI, M.; ALCALÁ, L. (1990) El género Hipparion en la fosa de Alfambra-Teruel. Paleontologia Evolució, vol. 23, 1990, pp. 105-110

- ALBERDI, M. T.; LÓPEZ MARTÍNEZ, N.; MORALES, J.; SESÉ, C.; SORIA, D. (1981) Bioestratigrafía y Biogeografía de la fauna de mamíferos de Los Valles de Fuentidueña (Segovia). Estudios Geológicos, vol. 37, 1981, pp. 503-511

- AlBERDI, M.; MORALES, J. (1981) Significado bioestratigráfico del género Hipparion en España. Teruel, vol. 66, pp. 61-66.

- ALCALÁ MARTíNEZ, L. (1994) Macromamíferos neógenos de la fosa de Alfambra-Teruel. Teruel: Museo Nacional de Ciencias Naturales, 1994

- AlCALÁ, L.; MONTOYA, P. (1990) Las faunas de macromamíferos del Turoliense inferior español. Paleontologia Evolució, vol. 23, 1990, pp. 111-119

- ALCALÁ, L.; MORALES, J.; SORIA, D. (1990) El registro fósil neógeno de los carnívoros (Creodonta y Carnívora, Mammalia) de España. Paleontologia Evolució, vol. 23, 1990, pp. $67-73$

- ASTIBIA, H. (1987) Los macromamíferos del Mioceno medio de Tarazona de Aragón (Depresión del Ebro, provincia de Zaragoza). Paleontologia Evolució, vol. 21, 1987, pp. 11- 42

- AZANZA, B.; MENÉNDEZ, E. (1990) Los ciervos fósiles del neógeno español. Paleontologia Evolució, vol. 23, 1990, pp. $75-82$

- CASANOVAS-VILAR, I.; MADERN, A.; ALBA, D. M.; CABRERA, L.; GARCÍA-PAREDES, I.; VAN DEN HOEK OSTENDE, L. W.; DEMIGUEL, D.; ROBLES, J. M.; FURIÓ M.; VAN DAM, J.; GARCÉS, M.; ANGELONE, C.; MOYÀSOLÀ, S. (2016) The Miocene mammal record of the VallèsPenedès Basin (Catalonia). Comptes Rendus Palevol, vol. 15, n. ${ }^{\circ} 7,2016$, pp. 791-812

- CRUSAFONT, M. (1950) La cuestión del llamado Meótico español. Arrahona, vol. 1, 1950, pp. 3-9

- DAAMS, R.; FREUDENTHAL, M.; VAN DER WEERD, A. (1977) Aragonian, a new stage of continental deposits of Miocene age. Newsletters on Stratigraphy, vol. 6, n. $^{\circ} 1$, 1977, pp. 42-55

- DAAMS, R.; FREUDENTHAL, M.; ÁLVAREZ-SIERRA, M. (1981) Ramblian: A new stage for continental deposits of early Miocene age. Geologie en Mijnbouw, vol. 65, pp. 297-308

- EISENMANN, V.; GUERIN, C. (1992) Tapirus priscus Kaup from the Upper Miocene of western Europe: palaeontology, biostratigraphy and palaeoecology. En AGUSTÍ, J. (coord.) Global Events and Neogene Evolution of the Mediterranean. Paleontologia Evolució, vol. 24-25, 1992, pp. 113-122

- FREUDENTHAL, M. (1966) On the mammalian fauna of the Hipparion-beds in the Calatayud-Teruel Basin (prov. Zaragoza, Spain). Part 1. The genera Cricetodon and 
Ruscinomys (Rodentia). Proceedings of the Koninklijke Nederlandse Akademie van Weteschappen, vol. 69, n. ${ }^{\circ} 2$, 1966, pp. 296-317

- FREUDENTHAL, M. (1968) On the mammalian fauna of the Hipparion-beds in the Calatayud-Teruel Basin (prov. Zaragoza, Spain). Part 4. The genus Megacricetodon (Rodentia). Proceedings of the Koninklijke Nederlandse Akademie van Weteschappen, vol. 71, n. ${ }^{\circ} 1,1968$, pp. 5772

- GARCÉS, M.; CABRERA, L.; AGUSTí, J.; PARÉS, J. M. (1997) Old World first appearence datum of "Hipparion" horses: late Miocene large mammal dispersal and global events. Geology, vol. 25, n. ${ }^{\circ} 1,1997$, pp. 19-22

- GARCÍA-ALIX, A.; MINWER-BARAKAT, R.; MARTÍN, J. M.; MARTÍN SUÁREZ, E.; FREUDENTHAL, M. (2008) Biostratigraphy and sedimentary evolution of late Miocene and Pliocene continental deposits of the Granada basin (southern Spain). Lethaia, vol. 41, 2008, pp. 431-446

- GINSBURG, L.; MORALES, J.; SORIA, D. (1994) The Ruminants (Artiodactyla, Mammalia) from the Lower Miocene of Cetina de Aragón (Province of Zaragoza, Aragón, Spain). Proceedings of the Koninklijke Nederlandse Akademie van Weteschappen, vol. 97, n. ${ }^{\circ} 2,1994$, pp. 141181

- MARTÍN-SUÁREZ, E.; OMS, O.; FREUDENTHAL, M.; PARÉS, J. M. (1998) Continental Mio-Pliocene transition in the Granada Basin. Lethaia, vol. 31, 1998, pp. 161-166

- MARTÍN-SUÁREZ, E.; GARCÍA-ALIX, A.; MINWERBARAKAT, R.; AGUSTÍ, J.; FREUDENTHAL, M. (2012) Filling the gap: first evidence of early Tortonian continental deposits in southern Iberia. Journal of Vertebrate Paleontology, vol. 32, n. ${ }^{\circ}$ 6, 2012, pp. 1421-1428

- MEIN, P.; MARTín-SUÁREZ, E.; AGUSTí, J. (1993) Progonomys Schaub, 1938 and Huerzelerimys gen. nov. (Rodentia); their evolution in Western Europe. Scripta Geologica, vol. 103, 1993, pp. 4164

- MINWER-BARAKAT, R.; GARCÍA-ALIX, A.; AGUSTÍ, J.; MARTÍN-SUÁREZ, E. (2009) The micromammal fauna from Negratín-1 (Guadix Basin, Southern Spain): new evidence of African-Iberian mammal exchanges during the late Miocene. Journal of Paleontology, vol. 83, n. ${ }^{\circ}$ 6, 2009, pp. 854-879

- MORALES, J. (1984) Venta del Moro: su macrofauna de mamíferos y bioestratigrafía continental del Mioceno terminal mediterráneo. Tesis doctoral inédita. Universidad Complutense de Madrid, pp. 340

- MORAlES, J.; AlCALÁ, L.; HOYOS, M.; SORIA, D. (1993) El yacimiento del Aragoniense medio de La Retama (Depresión Intermedia, Provincia de Cuenca, España): significado de las faunas con Hispanotherium. Scripta Geologica, vol. 103, 1993, pp. 23-39

- MORAlES, J.; L. GINSBURG; SORIA, D. (1986) Los Bovoidea (Artiodactyla, Mammalia) del Mioceno inferior de España: Filogenia y Biogeografía. Paleontologia Evolució, vol. 20, 1986, pp. 259-266

- MORALES, J.; POZO, M.; SILVA, P. G.; DOMINGO, M. S.; LÓPEZ-ANTOÑANZAS, R.; ÁLVAREZ SIERRA, M. A.; ANTÓN, M.; MARTÍN ESCORZA, C.; QUIRALTE, V; SALESA, M. J.; SÁNCHEZ, I. M.; AZANZA, B.; CALVO, J. P.; CARRASCO, P.; GARCÍA-PAREDES, I.; KNOLL, F.; HERNÁNDEZ FERNÁNDEZ, M.; VAN DEN HOEK OSTENDE, L.; MERINO, L.; VAN DER MEULEN, A. J.; MONTOYA, P.; PEIGNÉ, S.; PELÁEZ-CAMPOMANES, P.; SÁNCHEZ-MARCO, A.; TURNER, A.; ABELLA, J.; ALCALDE, G. M.; ANDRÉS, M.; DEMIGUEL, D.; CANTALAPIEDRA, J. L.; FRAILE, S.; GARCÍA YELO, B. A.; GÓMEZ CANO, A. R.; LÓPEZ GUERRERO, P.; OLIVER PÉREZ, A.; SILICEO, G. (2008) El sistema de yacimientos de mamíferos miocenos del Cerro de los Batallones, Cuenca de Madrid: estado actual y perspectivas. Seminario de Paleontología de Zaragoza, vol. 8, 2008, pp. 41-117

- MOYÀ-SOLÀ, S. (1987) Los Rumiantes (Cervoidea y Bovoidea, Artiodactyla, Mammalia) del Ageniense (Mioceno inferior) de Navarrete del Río (Teruel, España). Paleontologia Evolució, vol. 21, 1987, pp. 247-270

- MOYÀ-SOLÀ, S.; KOHLER, M. (1996) A Dryopithecus skeleton and the origin of great-ape locomotion. Nature, vol. 379, 1996, pp. 156-159

- SANTAFÉ, J. V.; CASANOVAS, M. L. (1982) Los Rinocerótidos (Mammalia, Perissodactyla) del Turoliense del Penedés (Piera, Barcelona). Butlletí Informatiu de l'Institut de Paleontologia de Sabadell, vol. 14, 1982, pp. 39-47

- VAN DER MADE. J. (1994) Suoidea from the lower Miocene of Cetina de Aragón (Spain). Revista Española de Paleontologia, vol. 9, n. ${ }^{\circ} 1,1994$, pp. 1-23

- VAN DER MADE. J. (1990) Iberian Suoidea. Paleontologia Evolució, vol. 23, 1990, pp. 83-98

- VAN DER MADE. J.; MORALES, J. (1999) Family Camelidae. En Rössner, G. E.; Heissig, K. (coord.) The Miocene land mammals of Europe. Munchen: Verlag F. Pfeil, 1999, pp. 221-224 